\title{
Moot punishments for Japanese STAP scientists
}

Lead author of retracted stem-cell papers is fired, and a co-author is suspended, from jobs they no longer held.

\section{David Cyranoski}

10 February 2015 I Updated: 11 February 2015

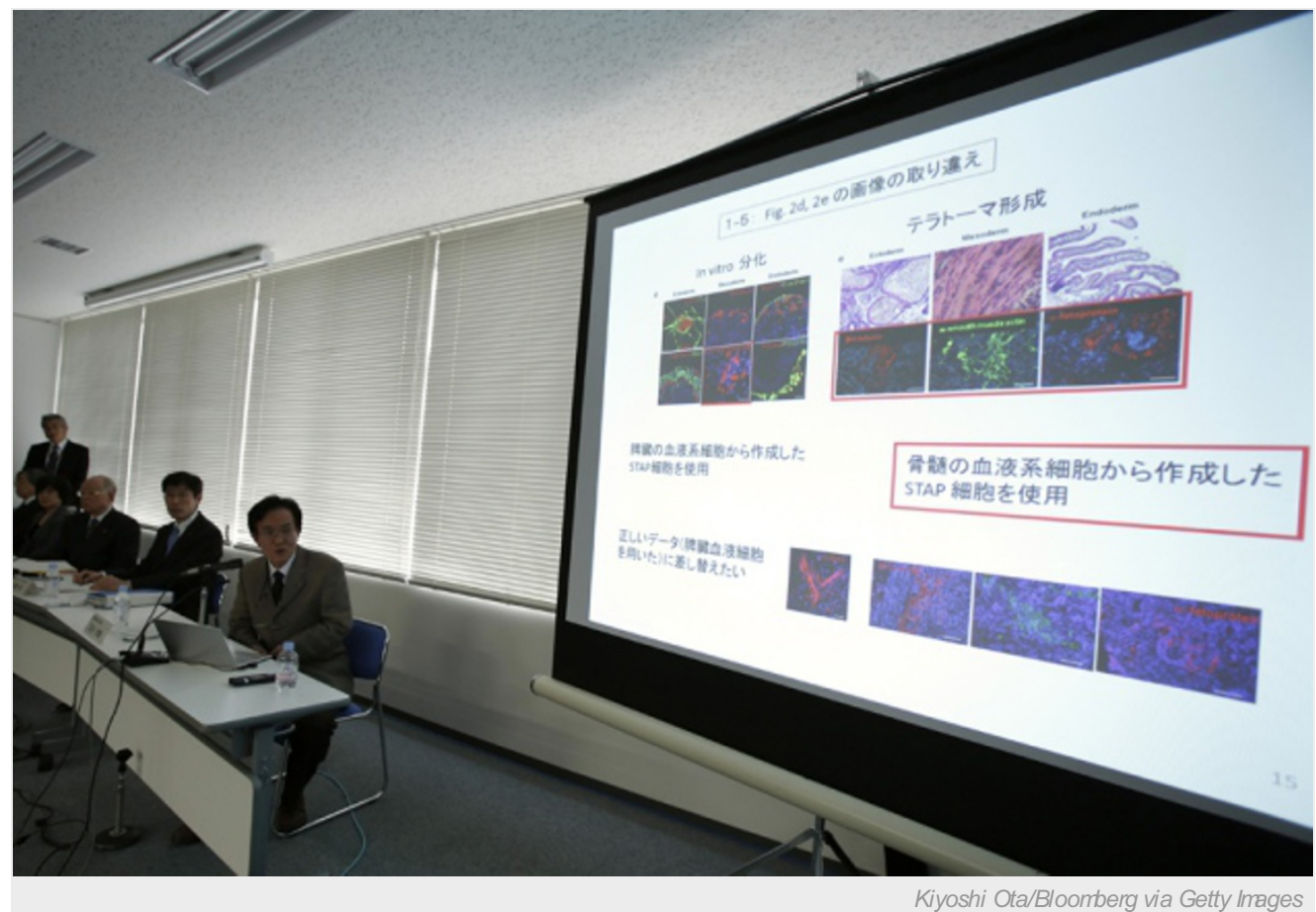

An investigation committee presenting an interim report on the STAP papers in Tokyo on 14 March, 2014.

Four Japanese biologists have been disciplined for their roles in a scandal that gripped Japan — and the international stem-cell science community - last year. The harshest punishments, however, went to two researchers who have since left the jobs in question.

The case involves two papers, published in Nature in January 2014 and later retracted, which detailed a process for creating embryonic-like stem cells, called stimulus-triggered acquisition of pluripotency, or STAP. The four researchers - three of whom were co-authors of the papers - all worked at the Center for Developmental Biology (CDB) in Kobe, and were disciplined by RIKEN, the research institution that oversees the CDB.

Haruko Obokata, the first author on the two papers and the key person in carrying out and coordinating the experiments, received the harshest punishment in RIKEN's rulings - she was dismissed from her position. That action, however, is moot because she had already resigned in December, after failing to reproduce the results. 
Teruhiko Wakayama, the famed mouse cloner who supervised Obokata when she first came to RIKEN in 2011, received a lesser penalty, suspension from work. Because he moved to the University of Yamanashi in 2012, that action is likewise moot. However, according to a press statement, Wakayama feels "an acute sense of responsibility" for the way things turned out, and has indicated that he wants to resign as the head of Yamanashi's developmental biology centre while carrying on as a researcher.

"RIKEN's [suspension of my position] does not apply because I no longer work there," Wakayama told Nature in an email. "But that would mean I suffered no penalty for failing in my responsibility as team leader." He added, "If by this measure the STAP fiasco comes to an end, the penalty does no bother me."

Hitoshi Niwa, another co-author whose involvement was limited to a few related experiments, received a warning.

Masatoshi Takeichi, who was the CDB's director from its founding in 2000 until he retired from the position last November, was given the lightest penalty - a reprimand. However, he voluntarily took the punishment of the next-most-severe penalty, which includes returning $10 \%$ of three months' salary.

In a statement, Takeichi, who remains a laboratory head at the CDB and special adviser to the centre, said, "I feel heavy responsible for failing to discover the misconduct and prevent unsuitable articles from being published. In the future, as a member of the scientific community, I plan to work even harder for the progress of proper scientific research."

On 11 February, a RIKEN spokesperson told Nature that the institute is also considering legal action against Obokata. Although it wil take several months for the details to be finalized, Japanese media are reporting that RIKEN might seek $¥ 15$ million (US\$125,000), in compensation for funding Obokata was given to try to replicate her results and other support used in the production of the original articles.

Nature I doi:10.1038/nature.2015.16904

\section{- Updates}

Updated:The article was updated to mention that RIKEN is considering legal action as well as to include quotes from Wakayama's email to Nature.

\section{SPRINGER NATURE}

